\title{
Design Construct and Evaluation of Six- Spectral LEDs-Based Solar Simulator Based on IEC 60904-9
}

\author{
Napat Watjanatepin ${ }^{\# 1}$ \\ ${ }^{\text {\#} S o l a r ~ E n e r g y ~ R e s e a r c h ~ a n d ~ T e c h n o l o g y ~ T r a n s f e r ~ C e n t e r ~(S E R T T) ~}$ \\ Faculty of Engineering and Architecture. \\ watjanatepin.n@gmail.com \\ ${ }^{1}$ Rajamangala University of Technology Suvarnabhumi Nonthaburi Thailand
}

\begin{abstract}
This article presents the optical design of a six-spectral LED-based solar simulator. The study focuses on the measurement methods of spectral match, the non- uniformity and the temporal instability on the test plane. The proposed six-spectral LED solar simulator has an illuminated area of $900 \mathrm{~cm}^{2}$ and can characterize medium size photovoltaic devices under variable irradiance. The spectral range covered is between $400 \mathrm{~nm}$ and $1100 \mathrm{~nm}$ which offer the capability of characterizing silicon PV technologies. The evaluation method is in accordance with IEC 60904-9. The Solar Power meter was used to measure the irradiance and a Compact Array Spectrometer and Fiber optic spectrometer were applied for the spectral match test. The irradiance is controlled via LabVIEW which can adjust the power to drive all LEDs in the constant current mode. The irradiance of $1000 \mathrm{~W} / \mathrm{m}^{2}$ was applied during testing. The results found that the spectral match classification is of class $\mathrm{B}$. The non-uniformity of irradiance is of A-class across the illuminated area. The temporal instability of irradiance is capable of reaching class $A$. This idea is perfectly appropriate for the application of the testing of I-V characteristic of the silicon solar cell. For future work, the author has to improve the spectral match to reach an A Class.
\end{abstract}

Keywords: Spectroradiometer,IEC 60904-9, Six-Spectral, LEDs-Based Solar Simulator

\section{INTRODUCTION}

Solar simulator is a light simulation providing illuminations close to the natural sunlight. Solar simulators are used for indoor testing, for example the V - I characteristic of solar cell or the PV Panel performance test. Solar simulator is divided into two types depending on the light source which are the conventional lamp (Xenon-arc, Halogen, Metal halide) and the light Emitting Diode (LED). The disadvantage of the conventional lamp is short life time ( 1,000 hours), complex optical device is needed, high power consumption, low luminous efficiency, and high maintenance cost.[1] On the other hand, LEDs have more specific advantage, such as high luminous efficiency, low operating voltage, low power consumption, long life time ( $\sim 5,000$ to 10,000 hours) and absence of complex optical devices. Moreover, the LEDs have specific light spectral, and is easier to control light intensity.

In the past decade, many authors have reported on the LED - base solar simulator and showed the characteristic of light generated that harmonizes with many standards (IEC, ASTM, JIS). To name a few, there was a report on a LED-solar simulator with nineteen spectral of LEDs to demonstrate the spectral in the A class with the luminance area of $5 \mathrm{~cm}$ in diameter with 1 sun.[1] Another is a solar simulation by eighteen spectral of LED [2] or a LED light simulation by six spectral with the small luminance area of $10 \times 10 \mathrm{~cm}^{2}$. [3] Furthermore, the hybrid light source between LED and halogen lamp with a A-class and B-class of spectral match was presented. [4]-[6]

IEC 60904-9 is the most popular standard which was applied to define the performance of the solar simulator. The standard listed three categories which are spectral match, non - uniformity of irradiance on the test area, and temporal instability of irradiance for I-V measurements. [16]

In this work, the author report on the design and evaluation of the solar simulator prototype based on six different spectral (cool white, warm white, UV 400nm, IR 740nm, IR 850nm, and IR 940nm). The author then applied two types of LED (Chip-on-board, High-power) to be the light source. The aim of this study is to demonstrate that the compact array of our six-spectral of LEDs is sufficient for the generation of high irradiance (at least 1 sun) on the test plane of $900 \mathrm{~cm}^{2}$, and authorinvestigate the spectral match, non-uniformity and temporal instability in accordance with the IEC 60904-9 standard. 


\section{LITERATURE REVIEW}

Kolberg.[7]was reported on a fully LED-based solar simulator for the PVindustry. The spectrum of a solar simulator was from 350 to $1100 \mathrm{~nm}$. Several spectrums of LEDs were applied to be the light source which includes visible light, Ultraviolet spectrum and Near Infrared spectrum. The temporal stability of the light intensity was $\pm 0.3 \%$.

Rumyantsev [8] developed a solar simulator that was used for the testing of the IV- characteristic of the $0.5 \times 1.0$ $\mathrm{m}^{2} \mathrm{HCPV}$ module (InGaP/GaAs/Ge), and silicone-on-glass Fresnel lens panels. This study used the light emitting diode as a light source and control in flash mode. The testing area was about $50 \times 100 \mathrm{~cm}^{2}$. Solar irradiance was $835 \mathrm{~W} / \mathrm{m}^{2}$. Light intensity was under flash illumination. The light source had a spectral uniformity within $\pm 4 \%$, with the light stability of $\pm 2 \%$.

Photong [9] was presented the Halogen-LED hybrid solar simulator that was used for studying the IVcharacteristic of the solar cell. Two 50-watts halogen lamps and 1024 LEDs with $0.5 \mathrm{~W}$ each (wavelength $450-$ 480 n.m.) was applied. This study was able to generate $1040 \mathrm{~W} / \mathrm{m}^{2}$ as maximum irradiance flux and match with the spectral match in class B (according with IEC 40904-9). The study could be applied to the $17 \times 17 \mathrm{~cm}^{2}$ of the test areas.

Bazzi.[3] reported the solid state solar simulator with six colors of the LEDs. The six-LEDs with difference light spectrum (between 400 to $1100 \mathrm{n}$.m.) were chosen to be the light source. The maximum irradiance was equal to $759 \mathrm{~W} / \mathrm{m}^{2}$ and the solar simulator operated on the test plane of about $10 \times 10 \mathrm{~cm}^{2}$. The ASTM standard was applied to test the quality of the solar simulator.

Grandi.[5]developed the hybrid LEDs-Halogen based solar simulator prototype which was used for solar cell characteristic tests. The spectral match is in class B (IEC 60904-9). The luminance flux maximum is 755 $\mathrm{W} / \mathrm{m}^{2}$ on the test area of about $20 \times 50 \mathrm{~cm}^{2}$.

Namin.[4] presented the LED solar simulators for the characterization of solar cells at moderate costs. Four single-color LED simulators and one multi-color LED simulators are constructed. High irradiance is obtained by employing high pulsing voltages to LEDs. Low cost LED simulators operated under pulse operations gave high irradiance close to $1000 \mathrm{Wm}^{-2}$. Irradiance uniformity and temporal instability quantify the five simulators as Class B. The solar simulator can test the I-V curves of on $12.5 \times 12.5 \mathrm{~cm}^{2}$ of the Solar cell.

Saadaoui.[10] reported the LEDs-halogen based solar simulator which was used to test the characteristic of Dye Sensitized solar cell. Their application is for the laboratory use.

Grandi.[11] presented the LEDs-Halogen-based Solar simulator with seven spectrums of LED. This simulator was used for the testing of the I-V characteristic of solar cell. The luminance was adjusted by using the voltage control technique. The maximumluminance is $590 \mathrm{~W} / \mathrm{m}^{2}$ and the test plane is about $12.5 \times 12.5 \mathrm{~cm}^{2}$. The quality of this solar simulator matched with Class ABB (IEC 60904-9).

Stuckelberger.[12] presented the class AAA LEDs-based solar simulator. The simulator is comprised of 11 colors of 19 LEDs (399-728 n.m.). The system is designed specifically for light soaking and current-voltage measurements of amorphous silicon solar cells. The reference spectrum was AM1.5g-with a spectral match corresponding to class $\mathrm{A}+$ or better. The concept of modular LED blocks and electronics guarantees good uniformity and easy up-scalability. Instead of cost-intensive LED drivers, low-cost power supplies were used with current control, including a feedback loop on in-house developed electronics. This prototype satisfies the highest classifications (better than AAA from 400 to $750 \mathrm{~nm}$ ) with an illuminated area of $18 \mathrm{~cm} \times 18 \mathrm{~cm}$ with the maximum irradiance of about $2,435 \mathrm{~W} / \mathrm{m}^{2}$

Novickovas.[1] reported on an efficient design of a light-emitting diode (LED)-based AAA class solar simulator, employing only 19 high-power emitters for a usable illuminated area of at least $5 \mathrm{~cm}$ in diameter with 1 sun irradiance. The number of LEDs used in this design was very low and was able to include several wavelengths of the LED groups (400- 950 n.m.) and taking advantage of wide emission angle for others. The socalled A class spectrum was also achieved for the larger area of more than $6 \times 6 \mathrm{~cm}^{2}$, covering zones with B and $\mathrm{C}$ class irradiance non-uniformity.

Schubert.[13] reported a comparative study of the three type solar simulator. There are 19-spectral LEDs solar simulator, Halogen solar simulator, and Xenon+Halogen solar simulator. The result was that a 19-LED solar simulator is comparable to an industry standard-filtered Xenon solar simulator. By improving the LED spectral tunability, better performance can be expected.

Leary [14] studied the performance of two different types of the solar simulators by comparing between the xenon lamp-based (Class : AAA) and led-based solar (Class :AAA) simulators. The I-V characteristics of the solar cells were tested in this study. The results demonstrated that the LED-based simulator produced a more stable, flexible, and accurate match to AM1.5G than the xenon lamp-based simulator with similar marks in the quality of PV cell response. 
Watjanatepin [15] presented the Chip-On-Board LEDs solar simulator. Eighteen 50-Watt COB LEDs (CCT: $3000 \mathrm{~K}, 6000 \mathrm{~K})$ were applied as light source. The non-uniformity of irradiance was approximately of Class: C on the test area of $224 \mathrm{~cm}^{2}$ (distance from the light source is about $25 \mathrm{~cm}$ ). The irradiance can be linearly adjusted from 0 to $769 \mathrm{~W} / \mathrm{m}^{2}$ via the LabVIEW. The solar simulator was applied for the laboratory use.

\section{MATERIAL AND METHOD}

\section{A.CAD design of the Six-Spectrums LEDs-Based Solar Simulator}

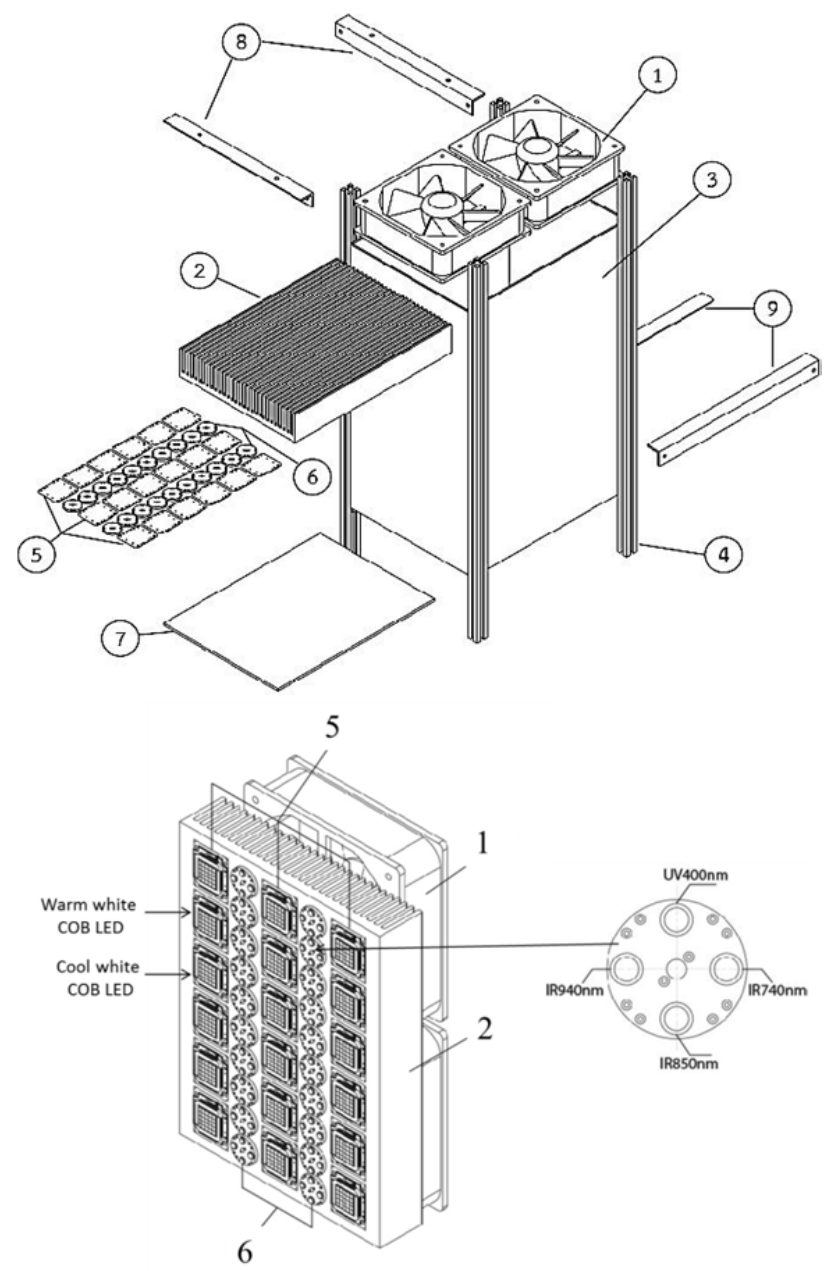

Fig.1. CAD design of the Six-Spectrums LEDs-Based Solar Simulator

The Six-Spectrums LEDs-Based Solar Simulator was designed by Solidworks2012. The major structures and components are (1) Cooling fan $(220 \mathrm{~V} / 50 \mathrm{~Hz} / 30 \mathrm{~W})(2)$ Aluminum heat $\operatorname{sink}(325 \mathrm{~mm} . \times 232 \mathrm{~mm} . \times 50 \mathrm{~mm})$. (3) Mirror wall (thickness $3 \mathrm{~mm}$, two of $240 \mathrm{~mm}$ x $455 \mathrm{~mm}$, and 2 of $320 \mathrm{~mm} \times 455 \mathrm{~mm}$ ). (4) Aluminum Profile pole 4 of $20 \mathrm{~mm} \times 20 \mathrm{~mm}$ ). (5)Nine of COB $50 \mathrm{~W}$ Warm-White and nine of COB $50 \mathrm{~W}$ Cool-White. (6) UVLED 3 W $410 \mathrm{~nm}$, IR-LED 3 W $740 \mathrm{~nm}$, IR-LED 3 W $850 \mathrm{~nm}$, IR-LED 3 W $940 \mathrm{~nm}$ totally 80 units. (7) Acrylic test plane with the size of $325 \mathrm{~mm} \times 232 \mathrm{~mm} \times 4 \mathrm{~mm}$. (8) Two aluminum rails with the dimension of 12 $\mathrm{mm} \times 12 \mathrm{~mm} \times 2 \mathrm{~mm}$ length $276 \mathrm{~mm}$. (9) Two aluminum rails with the dimension of $12 \mathrm{~mm} \times 12 \mathrm{~mm} \times 2 \mathrm{~mm}$ length $320 \mathrm{~mm}$.

\section{B. The Light source}

The light source of this study consists of

1) Warm-White COB-LED; Power 50 Watts, $V_{F}=32-34 V_{F}=1.5 A, C C T=3000 \mathrm{~K}$, Flux $=4000-5000$ $1 \mathrm{~m}$, wave length $380-730 \mathrm{~nm}$. (9 units)

2) Cool-White COB-LED; Power 50 Watts, $\mathrm{V}_{\mathrm{F}}=28-32, \mathrm{I}_{\mathrm{F}}=1.5 \mathrm{~A}, \mathrm{CCT}=6000 \mathrm{~K}, \mathrm{Flux}=4000 \mathrm{~lm}$, wave length N.A.(9 units)

3) UV LED Wavelength $410 \mathrm{~nm}, 3 \mathrm{~W}, \mathrm{~V}_{\mathrm{F}}=3.3-4.2 \mathrm{~V}, \mathrm{I}_{\mathrm{F}}=0.7 \mathrm{~A}$ diameter $8 \mathrm{~mm}$. (20 units)

4) IR-LED $700-800 \mathrm{~nm} 3 \mathrm{~W}, \mathrm{~V}_{\mathrm{F}}=1.5-1.7 \mathrm{~V}, \mathrm{I}_{\mathrm{F}}=0.7 \mathrm{~A}$ Wavelength $730-740 \mathrm{~nm} .(20$ units $)$

5) IR-LED $800-900 \mathrm{~nm} 3 \mathrm{~W}, \mathrm{~V}_{\mathrm{F}}=1.8-2 \mathrm{~V}, \mathrm{I}_{\mathrm{F}}=0.7 \mathrm{~A}$, Wavelength $850 \mathrm{~nm} .(20$ units)

6) IR-LED $900-1100 \mathrm{~nm} 3 \mathrm{~W}, \mathrm{~V}_{\mathrm{F}}=1.8-2 \mathrm{~V}, \mathrm{I}_{\mathrm{F}}=1.0 \mathrm{~A}$, Wavelength $940 \mathrm{~nm} .(20$ units $)$ 
The LEDs were installed on an aluminum anodize heat sink. There are thirty fins with the electric fan ventilation system at the back of the heat sink. (Figure.1) The luminance area is $295 \mathrm{~mm}$ x $210 \mathrm{~mm}$. There are three sets of high quality switching power supply to feed power to the LEDs. The diagram of the six- spectrums of LEDs (light source) is as shown in Figure 2. The mirror wall was installed inside of the test room as shown in Figure 2 .

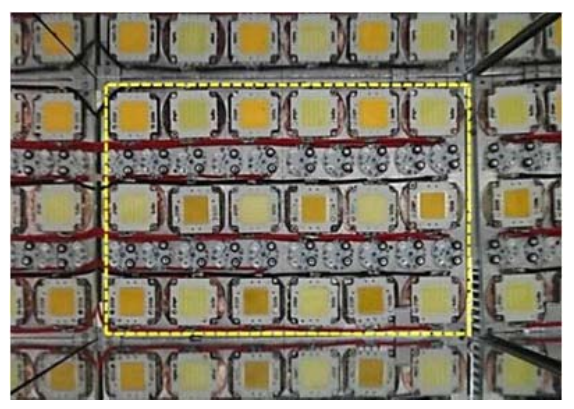

Fig.2. The light source and the mirror walls of the Six-Spectrums LEDs-Based Solar Simulator

\section{The control of the Light source}

The author used three sets of the switching power supply to drive the LEDs. (1) The PS-1 which has 36V/ 500 Watts to drive nine 50-Watts Warm-White COB-LED and nine 50-Watts Cool-White COB-LED.(2) The PS-2 has 36V/ 240 Watts to drive sixty 3-Watts of the UV-LED, IR $740 \mathrm{~nm}$, IR $850 \mathrm{~nm}$ LEDs.(3) The PS-3 has 36V/240 Watts to drive twenty 3-Watts of the IR $940 \mathrm{~nm}$ LEDs. LabVIEW was applied to control the irradiance of the six- spectrums of LEDs solar simulator as shown in Figure 3. The detail of the control program is not discussed in this study.

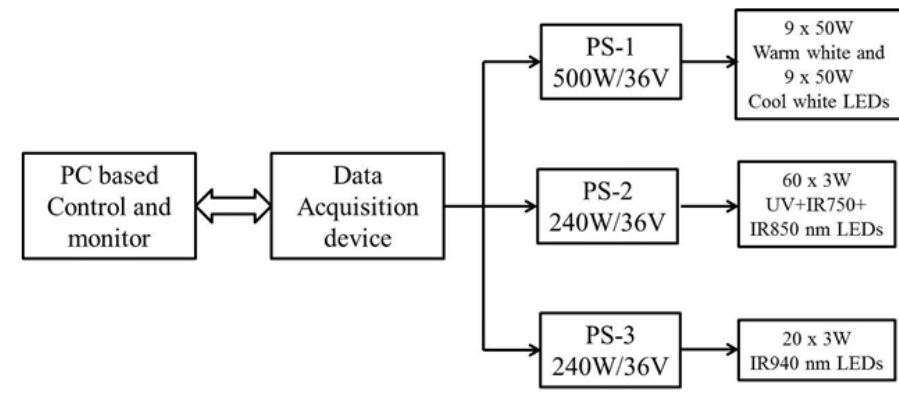

Fig.3. The control diagram of a Six-Spectrums LEDs-Based Solar Simulator

\section{D.The IEC 60904-9 Standard}

This study reference from the IEC 60904-9 (Photovoltaic device - Part 9: Solar Simulator Performance requirements). The IEC 60904-9 is the testing standard for testing the solar simulator for the indoor case. That is used for solar cell V-I characteristic test. This standard needs to test in the three categories. There is (a) The spectral match (b) The Non - uniformity of irradiance, and (c) The temporal instability of irradiance. [16]

\section{1) The spectral match}

The spectral match can measure by using the Spectroradiometer. That should measure the irradiance in each wave range of the band width of the light. (Band width, $\mathrm{nm}$ ) The measured results would compare with the standard value of AM $1.5 \mathrm{G}$ in each wave range band. Find out the percentage of the spectral match. The percentage of total irradiance is specified in Table I.

TABLE I.Global reference solar spectral irradiance distribution given in IEC 60904-3

\begin{tabular}{|c|c|c|}
\hline & $\begin{array}{c}\text { Wavelength } \\
\text { range(nm) }\end{array}$ & $\begin{array}{c}\text { Percentage of total irradiance in the } \\
\text { wavelength range } 400 \mathrm{~nm} .-1100 \mathrm{~nm} .\end{array}$ \\
\hline 1 & $400-500$ & $18.4 \%$ \\
2 & $500-600$ & $19.9 \%$ \\
3 & $600-700$ & $18.4 \%$ \\
4 & $700-800$ & $14.9 \%$ \\
5 & $900-1000$ & $12.5 \%$ \\
6 & $1000-1100$ & $15.9 \%$ \\
\hline
\end{tabular}




\section{2) The Non - uniformity of irradiance}

The non-uniformity of irradiance on the test plane is the percentage of the difference between the maximum irradiance and the minimum irradiance over the sum of maximum irradiance and minimum irradiance.According to the IEC 60904-9 standard[16] the test plane will bedivided into 64 equal size test positions $(8 \times 8)$. Then the irradiance is measured from each position and the minimum and maximum value of irradiance is taken to calculate the percentage of non-uniformity by using equation (1).

$$
\text { Non - uniformity }(\%)=\left[\frac{Q \max -Q \min }{Q \max +Q \min }\right] \times 100 \%
$$

$Q_{\max }$ is the measured value of the maximum irradiance $\left(\mathrm{W} / \mathrm{m}^{2}\right)$

$Q_{\min }$ is the measured value of a minimum irradiance $\left(\mathrm{W} / \mathrm{m}^{2}\right)$

\section{3) The temporal instability of irradiance}

The temporal instability of irradiance is distinguished into two types which are the short-term instability, (STI) and long-term instability, (LTI) which will depend on the type of the solar simulator. This study will be focused on the steady state solar simulator for I-V measurement.[16] The STI will be related with the data sampling time. The LTI will be related with the time of data acquisition that is measured for the I-V characteristic of the solar cell under test. The equation of temporal stability is as shown in equation (2).

$$
\text { Temporal - instability }(\%)=\left[\frac{Q \max -Q \min }{Q \max +Q \min }\right] \times 100 \%
$$

The IEC 60904-9 classified the standard of a solar simulator into three quality classes. There are Class A, Class $\mathrm{B}$, and Class C. Each class will define the percentage of the spectral match, non- uniformity of irradiance, and temporal instability of irradiance as shown in Table II.

TABLE II.Classification of the solar simulator in the IEC 60904-9 standard

\begin{tabular}{|c|c|c|c|}
\hline Class & Spectral Match & $\begin{array}{c}\text { Non-uniformity of } \\
\text { Irradiance }\end{array}$ & Temporal Instability \\
\hline A & $0.75-1.25 \%$ & $2 \%$ & $2 \%$ \\
B & $0.60-1.40 \%$ & $5 \%$ & $5 \%$ \\
C & $0.40-2.00 \%$ & $10 \%$ & $10 \%$ \\
\hline
\end{tabular}

\section{E. Non-uniformity of Irradiance and Temporal instability test procedure}

The non-uniformity testing procedure is based on IEC-60904-9 Edition 2.0 2007-10on page 10-11. The flowchart of the step by step procedure is shown in Figure 4.The temporal instability of the solar simulator used for the testing procedure is based on the IEC 60904-9 on page 11-13. The author tested two schemes which were (1) Short-term instability (STI) test and (2) Long- term instability (LTI) test. The LTI in this study is tested for 10 minute, and STI is tested on the pulse mode with $t_{o n}=t_{\text {off }}=10 \mathrm{~s}$. The sampling rate is 1 second. To measure the irradiance by using the Solar Power Meter model TES1333-R.

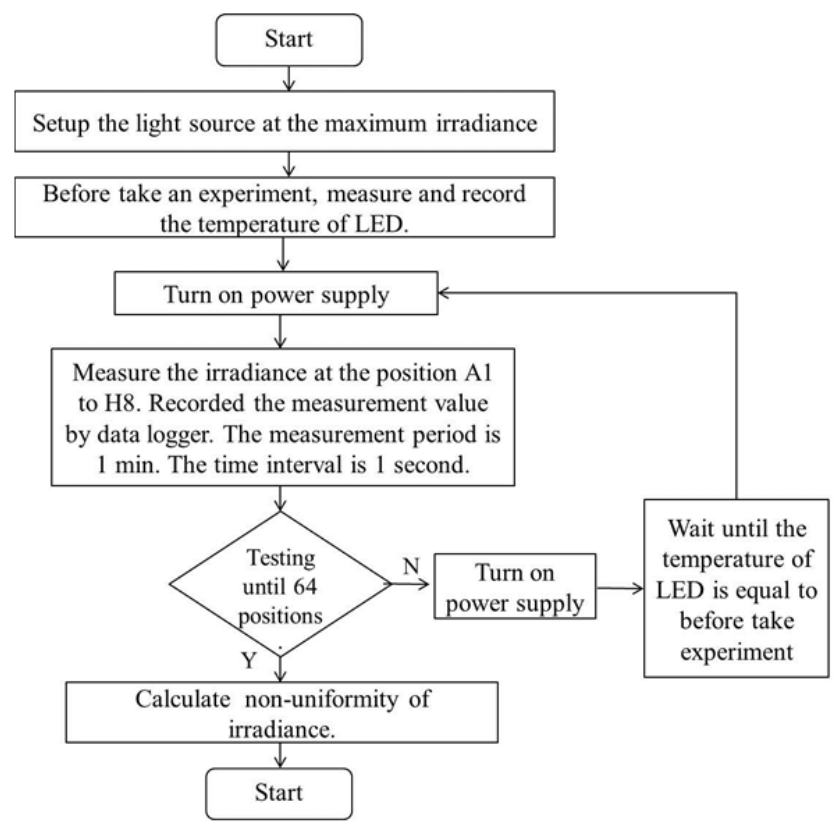

Fig.4. The experimental flow chart for test the non-uniformity of irradiance 


\section{F. Spectral match test}

The spectral measurement methods are based on IEC-60904-9 Edition 2.0 2007-10. The measurements were performed using two working diode-array spectrometers. They were previously calibrated. Turn on the solar simulator and set up the totally of irradiance is $1000 \mathrm{~W} / \mathrm{m}^{2}$. The Spectroradiometer that using in this study have two types. There are $400-960 \mathrm{~nm}$ of wavelength analyst by a Compact Array Spectrometer (Wavelength range: $\sim 220-1022 \mathrm{~nm} /$ accuracy: $\pm 0.3 \mathrm{~nm} /$ model: CAS140CT $-154 / \mathrm{S} / \mathrm{N}: 104614210)$, and for $960-1700 \mathrm{~nm}$ analyst by a Fiber optic spectrometer (Wavelength range: $960-1700 \mathrm{~nm} /$ accuracy: $\pm 1 \mathrm{~nm} /$ model: Read-wave NIR-25/ S/N: 10072611). The measurement data analyzed by the software Specwin-Pro and Spectra-Wiz. The experimental set up as in figure 5.The measurement was carried out at the laboratory in an ambient temperature of $(25.0 \pm$ $3.0){ }^{\circ} \mathrm{C}$ and relative humidity of $(50 \pm 20) \%$

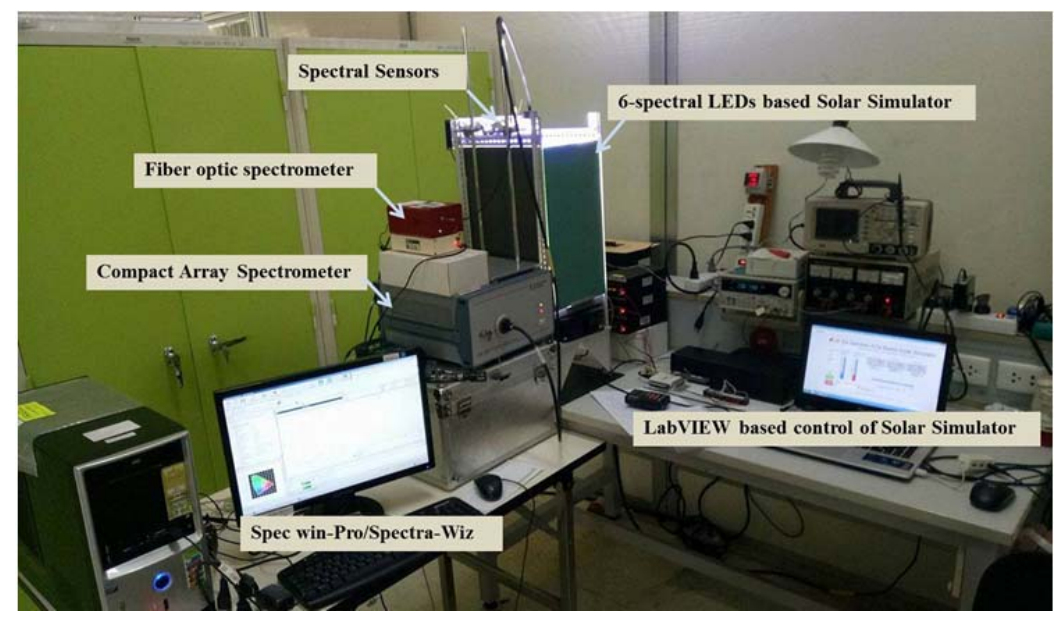

Fig.5.TheSpectral match test experimental setup.

\section{RESULTS AND DISCUSSION}

\section{A. Non-uniformity of irradiance}

The measured results of the irradiance from position A1 to $\mathrm{H} 8$ (64 positions in total) showed that the highest irradiance on the test plane is about $1013 \mathrm{~W} / \mathrm{m}^{2}$ at the position E5. The lowest is equal to 993 $\mathrm{W} / \mathrm{m}^{2}$ at the position $\mathrm{A} 1$. The average value of irradiance over the test plane is approximately 1003 $\mathrm{W} / \mathrm{m}^{2}$. The calculation results of non-uniformity on the test area of $32.5 \mathrm{~cm} \times 28 \mathrm{~cm}$ is equal to $1.915 \%$ which meets the IEC 60904-9 standard in Class: A. (Figure 6) The uniformity of the light source was very good because the author designed a symmetrical installing position for all the LEDs. According with the study of Stuckelberger.[12] Moreover, the author kept the distance between the light source and the test area to about 45 $\mathrm{cm}$ which is well positioned for an excellent non-uniformity. That conforms to the study of Watjanatepin[15] Shatat[17]and Mohan.[18] The mirror wall also contributed to the good results in non-uniformity of irradiance which, as mentioned previously, met class A.

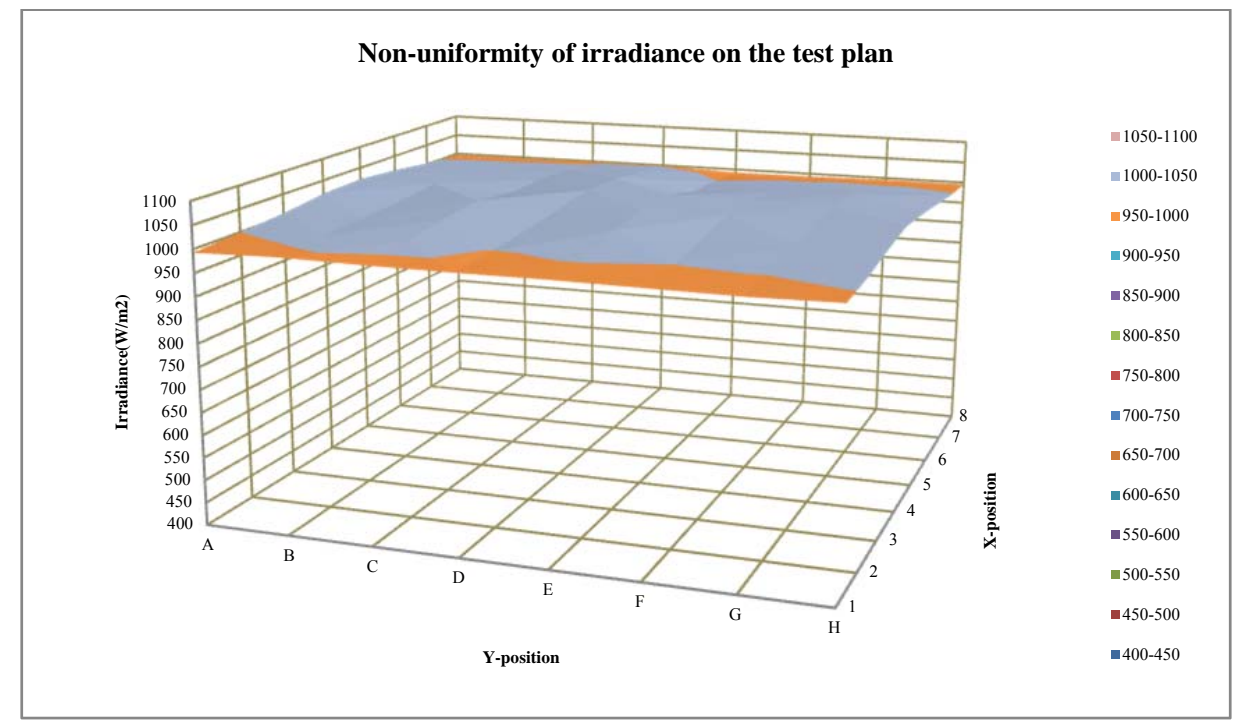

Fig.6.The pattern of the non-uniformity of irradiance on the testing results 


\section{B. Temporal instability}

\section{1) Long-term instability test}

The temporal stability of irradiance from the Six-Spectrums LEDs-Based Solar Simulator. This study using the Long-term instability testing method.(IEC $60904-9,2007$ )To turn on the power supply continue to $10 \mathrm{~min}$. and give a worm-up time of LED is about 20 seconds. The control of irradiance constant at 1000 $\mathrm{W} / \mathrm{m}^{2}$.The results found that the LTI is equal to $1.038 \%$.(Table III) This mean that the temporal stability of the irradiance by the continuous running. It is meet the Class: A of the IEC 60904-9. The measured results as shown in figure 7 .

TABLE III.Long-term instability calculation results

\begin{tabular}{|c|c|c|c|}
\hline \multirow{2}{*}{$\begin{array}{l}\text { Setup Irradiance } \\
\qquad\left(\mathrm{W} / \mathrm{m}^{2}\right)\end{array}$} & \multirow{2}{*}{$\begin{array}{c}\text { Calculation } \\
\text { Temporal instability }\end{array}$} & \multicolumn{2}{|c|}{ Measurement irradiance } \\
\hline & & Maximum & Minimum \\
\hline 1000 & 1.038 & 1017 & 996.1 \\
\hline
\end{tabular}

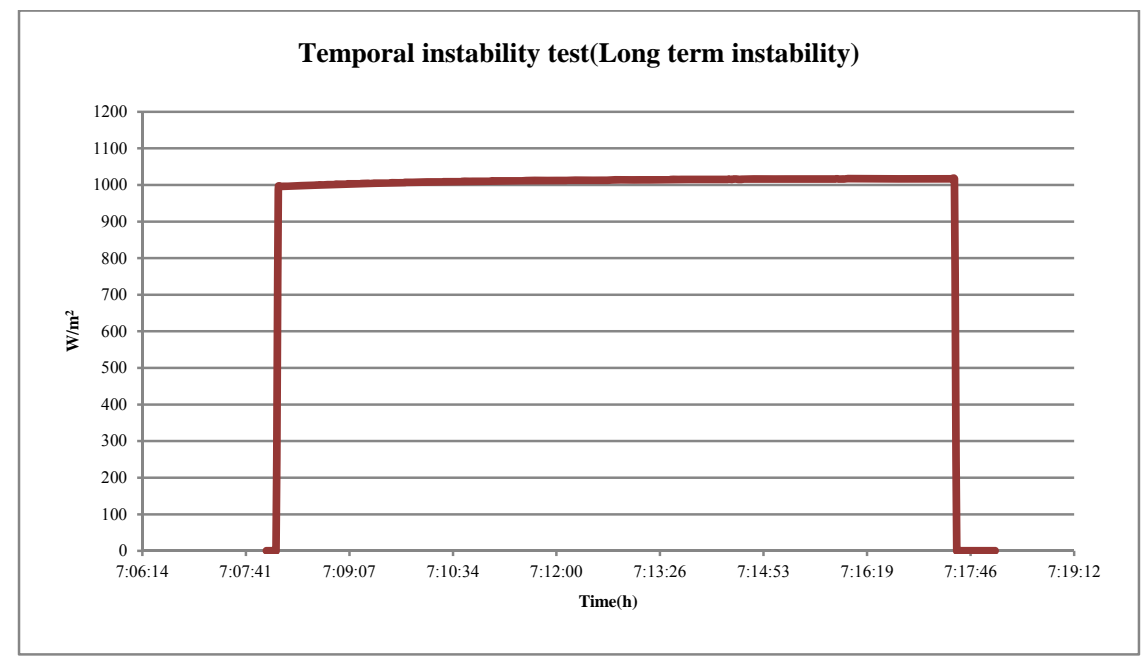

Fig.7.Long-term temporal instability testing results

\section{2) Short-term instability test}

The Short-term instability testing method. (IEC $60904-9,2007$ ) To turn on the power supply and set up the solar simulator generated the luminance in pulse mode (turn-on time10 s, duty cycle $50 \%$ ). No need to worm-up time of the LED before test. The control of irradiance constant at $1000 \mathrm{~W} / \mathrm{m}^{2}$. The measured pulse of the irradiance as show in figure 8. The calculated results (by equation 2) found that the STI is equal to $0.36 \%$. 0.29 $\%$ and $0.32 \%$. This means that the short-term temporal stability of the irradiance meets the Class: A of the IEC 60904-9. The technical design achieved satisfactory results of having a temporal instability. This is a good quality of a power supply. The author used low ripple power supply with the constant current control as the LED driver. This is in accordance with the study results of Bazzi [3] and the design of Novickovas [1] and Stuckelberger [12] whose results showed that the uniformity measurements were also in class A.

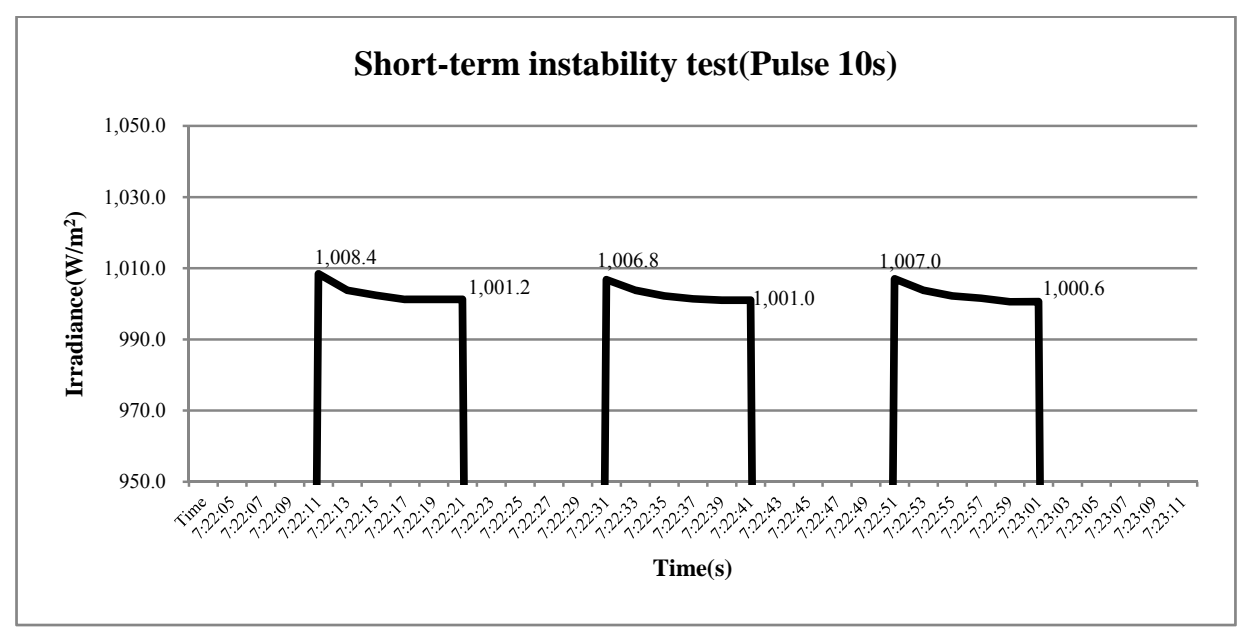

Fig.8.The Short-term temporal instability testing results 


\section{Spectral match}

The spectral match test results as analysis by the software (Specwin-Pro and Spectra-Wiz) then plot the relative spectral irradiance of the 6-spectral LEDs based solar simulator prototype as shown in figure 9. The calculation of the spectral match factor of a solar simulator prototype compare with the AM 1.5G was show in Table IV. The result show that the spectral match meet in Class B(IEC 60904-9). It is possible to improve the spectral match to reach an A-Class. From Table IV, the percentage of irradiance is too much in the range of 500-600 nm. The author could decrease the percentage of irradiance from 27.8 to 24.8 and the spectral match factor will be less than 1.25 or meet A-class. On the other hand, the author has to increase the irradiance of LED $940 \mathrm{~nm}$ from $9.96 \%$ to $11.96 \%$, which will also be able to make the spectral match reach Class A. A good solution is to separate the power supply to be 6 sets. Each power supply will control each LED type, this is in accordance with the idea of Bazzi.[3]In this case the authors can dependently control the percentage of irradiance in each range. This means that the author can increase or decrease the irradiance in 500-600 nm and 900-1100 nm to meet class A. Affect to the cost of solar simulator will increase.

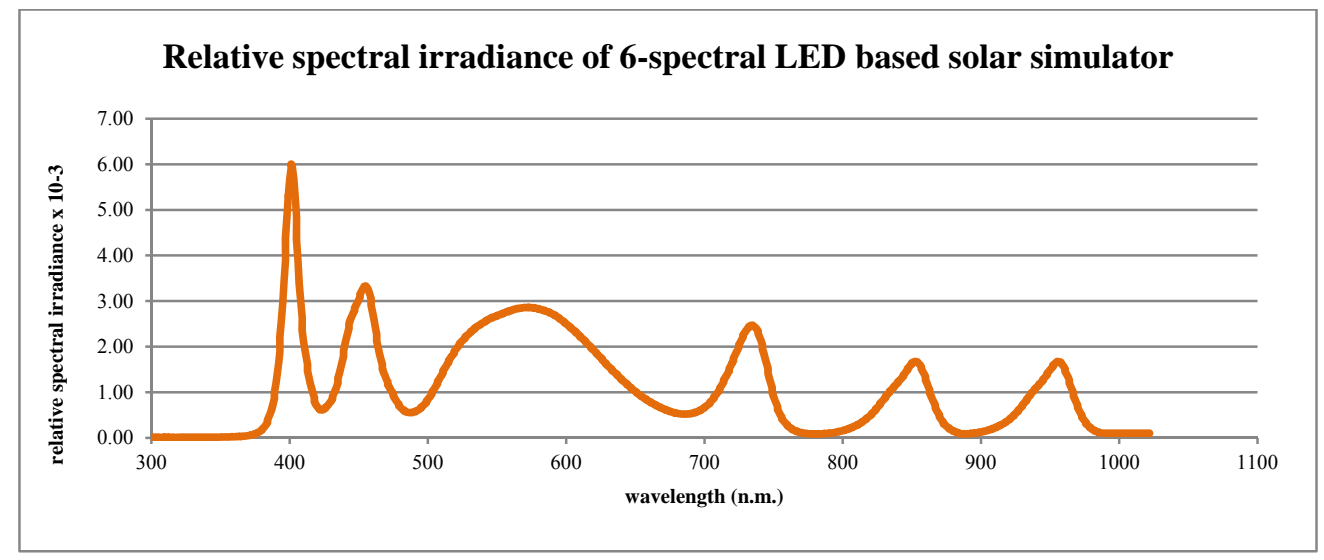

Fig. 9.Measurement result of a relative spectral irradiance of the solar simulator prototype

TABLE IV.The spectral match factor compare between AM 1.5G and solar simulator prototype

\begin{tabular}{|c|c|c|c|c|}
\hline \multirow{2}{*}{$\begin{array}{c}\text { Spectral range } \\
(\mathrm{nm})\end{array}$} & AM 1.5G & \multicolumn{3}{|c|}{ 6-Spectral LED based Solar simulator } \\
\cline { 2 - 5 } & \% of Irradiance & \% of Irradiance & Spectral match & Class \\
\hline $400-500$ & 18.4 & 22.61 & 1.229 & $\mathrm{~A}$ \\
\hline $500-600$ & 19.9 & 27.80 & 1.397 & $\mathrm{~B}$ \\
\hline $600-700$ & 18.4 & 16.95 & 0.921 & $\mathrm{~A}$ \\
\hline $700-800$ & 14.9 & 12.65 & 0.849 & $\mathrm{~A}$ \\
\hline $800-900$ & 12.5 & 10.03 & 0.802 & $\mathrm{~A}$ \\
\hline $900-1100$ & 15.9 & 9.96 & 0.626 & $\mathrm{~B}$ \\
\hline
\end{tabular}

\section{CONCLUSION AND OUT LOOK}

The six-spectral LEDs solar simulator is effective for the generation of high irradiance about $1000 \mathrm{~W} / \mathrm{m}^{2}$ on the test plane. There are six different LED types in this study (cool white, warm white, UV 410nm, IR 740nm, IR $850 \mathrm{~nm}$, and IR 940nm). This solar simulator reaches Class BAA on 400 to $1100 \mathrm{~nm}$ spectral range (IEC 609049 standard). This idea can reduce the number of the LED chips and the inactivation of complex optics was achieved. The prototype is a compact system with simplified LED circuit design. The prototype was demonstrated using six types of high-power LEDs. Only 98 LEDs are needed for a usable illuminated area of $900 \mathrm{~cm}^{2}$. This solar simulator is perfectly appropriate for testing the I-V characteristic of the medium size silicon solar cells.

The author has to improve the spectral match to reach A Class. Moreover, the author has innovating ideas for the design of the AAA Class of LED solar simulator by using five-spectral of LED and separate individual power supply for controlling the irradiance of each type of LEDs for future work.

\section{ACKNOWLEDGEMENT}

Authors wish to acknowledge their gratitude to the anonymous reviewers who gave freely time and effort, constructive recommendations that enhanced the value of this manuscript. The authors also would like to thank for the research budgets from the National Research Council of Thailand on the year 2016. (Project Code 2560A17203001) 


\section{REFERENCES}

[1] A. Novičkovas, A. Baguckis, A. Mekys and V. Tamošiūnas, Compact Light-Emitting Diode-Based AAA Class Solar Simulator: Design and Application Peculiarities, IEEE Journal of Photovoltaics, 2015, vol. 5, no. 4, pp.1137-1142.

[2] Kerbs F. C., K. S.-H. (2011). A self-calibrating led-based solar test platform.Prog.Photovolt : Res.Appl.2011, 19:97-112.

[3] A.M. Bazzi, Z. Klein, M. Sweeney, K.P. Kroeger, P.S. Shenoy, P.T. Krein, Solid-State Solar Simulator, Industry Applications, 2012 , vol. 48, pp. 1195-1202

[4] Anon Namin, ChayaJivacate, DhirayutChenvidhya, KrissanapongKirtikara, JutturitThongpron, Determinationof solar cell electrical parameters and resistances using color and white LED-based solar simulators with high amplitude pulse input voltages, Renewable Energy,Volume 54, June 2013, Pages 131-137, ISSN 0960-1481,

[5] G. Grandi and A. Ienina, Analysis and Realization of a Low-Cost Hybrid LED-Halogen Solar Simulator, International Conference on Renewable Energy Research and Applications, 2013, pp. 794-799.

[6] Bliss M., T. B. (2009). An LED-based photovoltaic measurement system with variable spectrum and flash speed. Solar Energy Materials \& Solar cell 93, 825-830.

[7] D. Kolberg, F. Schubert, N. Lontke, A. Zwigart, D.M. Spinner, Development of tunable close match LED solar simulator with extended spectral range to UV and IR, Energy Procedia, Volume 8, 2011, Pages 100-105, ISSN 1876-6102

[8] V. D. Rumyantsev, V. R. Larionov, D. A. Malevskiy, P. V. Pokrovskiy and N. A. Sadchikov, Solar Simulator For Characterization Of The Large-Area HCPV Modules, 7th International Conference on Concentrating Photovoltaic Systems: Cpv-7, AIP Conference Proceedings, 2011.

[9] A.Photong, Y.Kantawong, A.Somrak, A.Jamjang and A.Namin. Development of Solar Simulator for Investigate a Solar cell.Proceeding conference of The 4th Science Research Conference, 12 - 13 March 2012 Naresuan University Thailand.

[10] S. Saadaoui, A. Torchani, T. Azizi, and R. Gharbi, Hybrid halogen-LED sources as an affordable solar simulator to evaluate Dye Sensitized Solar Cells, Sciences and Techniques of Automatic Control and Computer Engineering (STA), 2014, pp. 884-887. [6] Z. Salam, M.Z. Ramliand T Zainal, A Low Cost Solar Array Simulator Using Halogen Tungsten Bulb with Temperature Control Capability, Energy Conversion (CENCON), 2014, pp. 170-174.

[11] G. Grandi, Effective Low-Cost Hybrid LED-Halogen Solar Simulator, IEEE Transactions on Industry Applications, 2014, vol. 50, no. 5, pp. 3055-3064. [13] Felix Schubert, Daniel Spinner, Solar Simulator Spectrum and Measurement Uncertainties, Energy Procedia, Volume 92, August 2016, Pages 205-210, ISSN 1876-6102

[12] M. Stuckelberger, B. Perruche, M. Bonnet-Eymard, Y. Riesen, M. Despeisse, F.-J. Haug, and C. Ballif, Class AAA LED-Based Solar Simulator for Steady-State Measurements and Light Soaking, IEEE Journal of Photovoltaics, 2014, vol. 4, no. 5, pp. 1282-1287

[13] Felix Schubert, Daniel Spinner, Solar Simulator Spectrum and Measurement Uncertainties, Energy Procedia, Volume 92, August 2016, Pages 205-210, ISSN 1876-6102

[14] G. Leary, G. Switzer, G. Kuntz and T. Kaiser, "Comparison of xenon lamp-based and led-based solar simulators," 2016 IEEE $43^{\text {rd }}$ Photovoltaic Specialists Conference (PVSC), Portland, OR, USA, 2016, pp.3062-3067.

[15] Napat Watjanatepin. (2016) FABRICATION AND STUDY OF NON-UNIFORMITY OF SINGLE COLOR CHIP-ON-BOARD LED SOLAR SIMULATOR. Academic Journal of Science, ISSN: 2165-6282 :: 05(01):227-236

[16] IEC, IEC 60904 - 9 Photovoltaic devices - Part g. Solar Simulator Performance requirement, edition 2.0, 2007, pp.1 - 30

[17] M. Shatat, S. Riffat and F. Agyenim, Experimental testing method for solar light simulator with an attached evacuated solar collector, International Journal of Energy and Environment (IJEE), 2013, vol. 4, pp. 219-230.

[18] Abhay Mohan, M.V.; Pavithran, J.; Osten, K.L.; Jinumon, A.; Mrinalini, C.P., (2014) "Simulation of spectral match and spatial nonuniformity for LED solar simulator," in Global Humanitarian Technology Conference - South Asia Satellite (GHTC-SAS), 2014 IEEE, vol., no., pp.111-117, 26-27 Sept. 2014

\section{AUTHOR PROFILE}

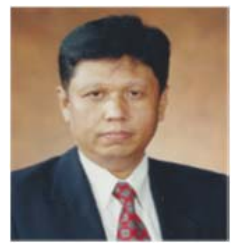

Napat Watjanatepin, professor (Associate) in Electrical Engineering. Education B.S.Tech.Ed. (Electrical Engineering) Institute of Technology Vocational Education(ITVE), Thailand (1985) M.S.Tech.Ed (Electrical Technology) King Mongkut's Institute of Technology North Bangkok, Thailand (1991).Research interest photovoltaic energy system, pc based monitor system, power electronics, engineering education publication 36 of the books (in Thai), 10 of national journals, 19 of national conferences, 8 of international journals, and 35 of international conferences. 